\title{
Increasing Student Curiosity with Cooling Systems
}

\section{Dr. Jordan Farina, University of Portland \\ Dr. Heather Dillon, University of Portland}

Dr. Heather Dillon is an Associate Professor in Mechanical Engineering at the University of Portland. She recently served as the Fulbright Canada Research Chair in STEM Education. Her research team is working on energy efficiency, renewable energy, fundamental heat transfer, and engineering education. Before joining the university, Heather Dillon worked for the Pacific Northwest National Laboratory (PNNL) as a senior research engineer.

\section{Rebecca D Levison, University of Portland}

Rebecca Levison is a graduate research fellow working on her doctorate in education at the University of Portland. As a research fellow, Rebecca works on a KEEN assessment project and partnership between the School of Education and the School of Engineering to improve engineering education. When not working on the KEEN project, she works full time for Portland Public Schools as an ESL Teacher on Special Assignment. In that role, Rebecca writes science curriculum accessible to language learners that aligns with the Next Generation Science Standards and trains teachers how to implement new strategies for all learners.

\section{Dr. Nicole Ralston, University of Portland}




\section{Increasing Student Curiosity with Cooling Systems}

\section{Abstract}

The purpose of this research was to develop a classroom project module that increased student curiosity about cooling systems. The module was designed to help students connect with psychrometrics near the end of an applied thermodynamics course. Traditionally, many students struggle with the concepts covered in this unit of the course. The module was designed to lead the students to the working principles behind a swamp cooler by using the biological process of sweating as an example of a way to remove energy due to mass transfer. A student survey was developed and measured student perceptions about the new classroom module. Students reported they found the activities most helpful for helping them connect knowledge in the course with real world systems.

\section{Introduction}

This paper describes a classroom module designed to increase engineering student skills in thermodynamics, specifically for psychrometrics. This module was designed to increase student curiosity by allowing students to learn about psychrometrics independently before a standard lecture. The module's problem statement was designed to lead the students to the working principles behind a swamp cooler by using the biological process of sweating as an example of a way to remove energy due to mass transfer.

The module developed had several learning objectives:

1. Recognize and explore knowledge gaps. [curiosity]

2. Explore multiple solution paths. [curiosity]

3. Identify and describe links between course knowledge and real-world systems. [connections]

The research goal of the project was to determine if a structured module in an engineering course could help students engage more fully with psychrometrics. This module is also part of a larger effort at the University of Portland to embed the entrepreneurial mindset [1] across the curriculum. The entrepreneurial mindset includes helping students connect engineering topics with real world systems and building curiosity about systems. The learning objects of this module were aligned with this idea, and backward design was used to develop the evaporative cooling module.

\section{Background}

Thermodynamics students often struggle with the topic of psychrometrics. The topic has been addressed by some prior authors as shown in Table 1. Most used laboratory experiments or software as a method to help students engage with the topic [2-4]. A few focused on active learning in the classroom with an emphasis on psychrometric charts $[5,6]$. Coronella used evaporative cooling as the focus of a first-year engineering design course [7]. 
Table 1. Summary of psychrometric focused engineering education methods from the literature.

\begin{tabular}{|c|c|c|c|}
\hline Author & Year & $\begin{array}{l}\text { Pedagogical } \\
\text { Elements }\end{array}$ & Thermodynamic Focus Area \\
\hline $\begin{array}{l}\text { Somerton and } \\
\text { Genik [5] }\end{array}$ & 2006 & $\begin{array}{l}\text { Active learning } \\
\text { handout }\end{array}$ & $\begin{array}{l}\text { Psychrometric calculations and } \\
\text { charts }\end{array}$ \\
\hline $\begin{array}{l}\text { Maixner and } \\
\text { Baughn [2] }\end{array}$ & 2007 & Laboratory & $\begin{array}{l}\text { Psychrometric software (excel } \\
\text { based) }\end{array}$ \\
\hline $\begin{array}{l}\text { Shepard and George } \\
{[3]}\end{array}$ & 2010 & Laboratory & Desalination design project \\
\hline $\begin{array}{l}\text { Peuker and Peuker } \\
{[4]}\end{array}$ & 2013 & $\begin{array}{l}\text { Virtual Labs and } \\
\text { active learning }\end{array}$ & $\begin{array}{l}\text { Psychrometric software (EES } \\
\text { based) }\end{array}$ \\
\hline $\begin{array}{l}\text { Kresta and Ayranci } \\
\text { [6] }\end{array}$ & 2018 & Active learning & Reading psychrometric charts \\
\hline Berman et al. [8] & 2019 & Edutainment & $\begin{array}{l}\text { HVAC applications of } \\
\text { psychrometrics }\end{array}$ \\
\hline This Study & 2019 & Active learning & $\begin{array}{l}\text { Psychrometrics and entrepreneurial } \\
\text { mindset }\end{array}$ \\
\hline
\end{tabular}

None of the prior works in engineering education have focused on the development of both student connections and the entrepreneurial mindset.

\section{Module Design}

This module was designed for a junior level required class on applied thermodynamics, the second course in the thermodynamics sequence. There were 65 students in the class, most of whom were majoring in mechanical engineering. The students worked as individuals. The module was implemented in a lecture course during the second half of the course, after students had already been introduced to the concepts of gas mixtures and the fundamentals of engineering and thermodynamics.

Prior to the module, students had knowledge of control volume analysis, conservation of mass and energy, and an introduction to ideal gas mixtures. Lecture materials and homework prior to the module included most standard material on cycles and energy analysis typically found in an introduction to thermodynamics, and applied thermodynamics.

After the students were introduced to ideal gas mixtures and solution techniques for closed systems and control volumes, the inquiry-based module on psychrometrics was assigned. This assignment preceded any discussion on psychrometrics or any mixture problem that included a phase change. The assignment was a single problem that asked the students to consider how they could cool their dorm room when the outside conditions reached $104^{\circ} \mathrm{F}$ and $10 \%$ humidity, using only a fan, water, and items typically found in a dorm room. They were prompted to think about how their own body regulates its temperature when the ambient conditions are above $98.6^{\circ} \mathrm{F}$. From their experience and knowledge of heat transfer, they know that all modes of heat transfer could not be used to cool their body due to the adverse temperature gradient. A few prompts were given to them to get them thinking, including the following: How does the body cool down? Their immediate thought was sweating. But, how does water at your body temperature cool you down? Again, their response was evaporative cooling. While the expectation was for 
them to quickly identify the physical mechanism responsible for this process, the goal was that, in the context of an Applied Thermodynamics course, they learn to formulate this into a problem that can be "solved" or used in an engineering application. The goal of this project was to encourage students to explore and discover answers to questions such as: "how does mass transfer remove energy?", "what drives the evaporation/phase change if there is no or possibly an adverse temperature gradient?", "can water vapor be treated as an ideal gas?", "are there limits on the amount of mass transfer possible for certain conditions?", and "how does humidity play in to this?" The success of this module hinged on the students' curiosity. Common everyday experiences can easily be overlooked (and assumed understood) until the students questioned them in detail.

The students were given approximately three weeks to complete the assignment. The single problem assignment was substituted for the standard textbook homework set that was typically assigned for each section. During the weeks the students were working on the assignment, standard lectures on psychrometrics and example problems were presented. While never directly mentioning the assignment, many topics were discussed that led students to "aha moments", allowing them to get over the hurdles they were currently facing with the assignment. The submission date of the assignment corresponded to the conclusion of the formal lectures on the topic.

\section{Assessment Methods}

To determine if students had met the learning objectives the module was designed to address, a student survey was developed. Table 2 gives an example of the type of survey questions students were asked. The questions were modified slightly for each objective.

Table 2. Example of a student survey questions where students were asked to consider each learning objective on a Likert scale.

For the learning objective listed below, please rank the extent to which your capacity increased during this class. (circle one) Then, please elaborate with a specific example.

\begin{tabular}{|c|c|c|c|c|c|}
\hline Question & $\begin{array}{l}\text { Not } \\
\text { at all }\end{array}$ & $\begin{array}{l}\text { Very } \\
\text { Little }\end{array}$ & $\begin{array}{l}\text { To a } \\
\text { Small } \\
\text { Extent }\end{array}$ & $\begin{array}{l}\text { To a } \\
\text { Moderate } \\
\text { Extent }\end{array}$ & $\begin{array}{l}\text { To a } \\
\text { Great } \\
\text { Extent }\end{array}$ \\
\hline $\begin{array}{l}\text { To what extent has your ability } \\
\text { to identify links between course } \\
\text { knowledge and real world } \\
\text { systems increased during this } \\
\text { class? }\end{array}$ & 1 & 2 & 3 & 4 & 5 \\
\hline
\end{tabular}

Describe a specific example of how your ability to identify links between course knowledge and real world systems increased in this class. 


\section{Results}

The student survey was completed by 50 students in the spring of $2019,79 \%$ of the total student enrollment. All of the student respondents were mechanical engineering majors. The summary of the Likert questions has been included in Table 3 and Figures 1-3. Students were asked to rank the learning objectives on a Likert scale of 1 to 5 where 1 was the worst ranking and 5 was the best ranking.

Table 3. Summary of the Likert question results in the student survey.

\begin{tabular}{|c|c|c|c|}
\hline Objective & $n$ & Mean & $\begin{array}{l}\text { Standard } \\
\text { Deviation }\end{array}$ \\
\hline $\begin{array}{l}\text { Ability to recognize and explore knowledge } \\
\text { gaps }\end{array}$ & 50 & 3.51 & 0.88 \\
\hline Ability to explore multiple solution paths & 50 & 3.56 & 1.03 \\
\hline $\begin{array}{l}\text { Identify links between course knowledge and } \\
\text { real world systems }\end{array}$ & 50 & 4.15 & 0.70 \\
\hline
\end{tabular}

In general, the students ranked the objectives well, with the lowest score for the objective about exploring knowledge gaps. This might indicate ways to improve the module in future course offerings. The highest value was given to identifying links between course knowledge and real world systems. Students rankings were statistically significantly higher for "identify links between course knowledge and real world systems" $(p<.05)$ when compared to the other learning objectives.

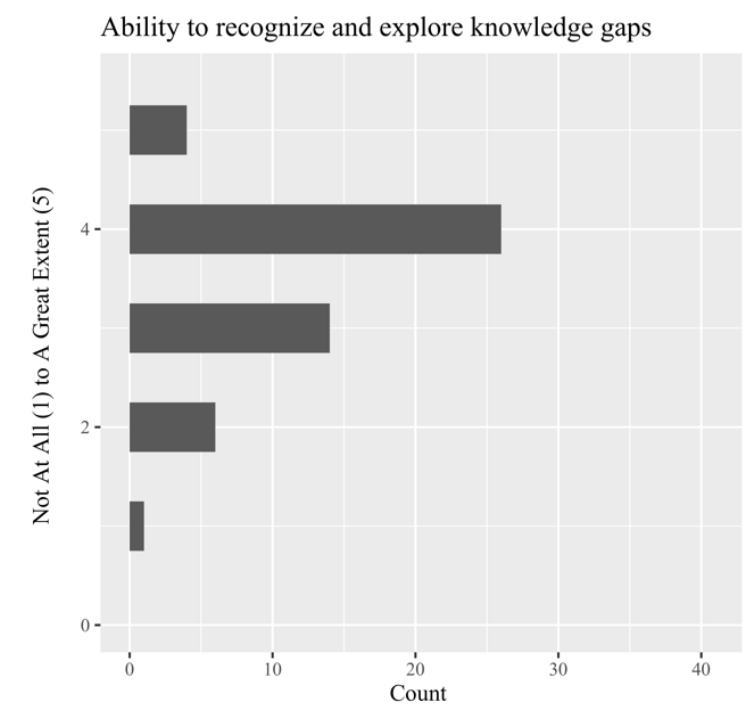

Figure 1. Student responses to the learning objective "Ability to recognize and explore knowledge gaps".
Identify links between course knowledge and real world

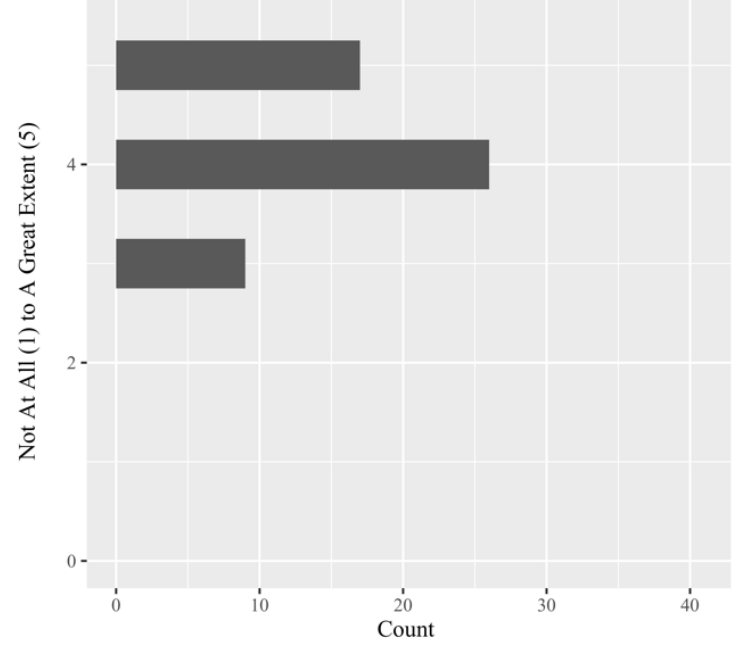

Figure 2. Student responses to the learning objective "Identify links between course knowledge and real-world systems".

For each learning objective, students were also asked to describe a specific example. The student essays were summarized using a natural language processor and a word cloud of the responses, 
which is shown in Figure 4. Students highlighted terms like "knowledge" and "problems", words that were well aligned with the goals of the module.

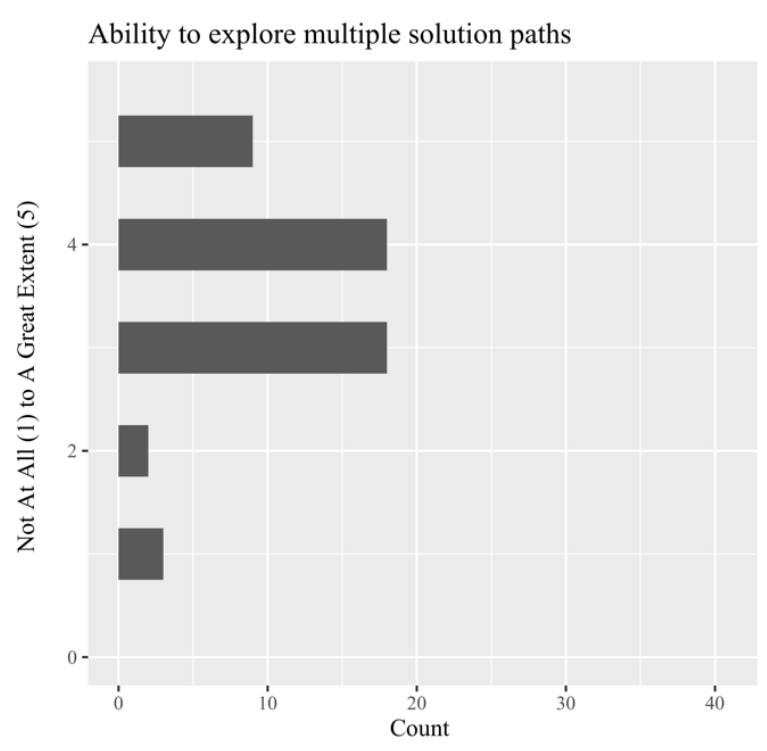

Figure 3. Student responses to the learning objective "Ability to explore multiple solution paths".

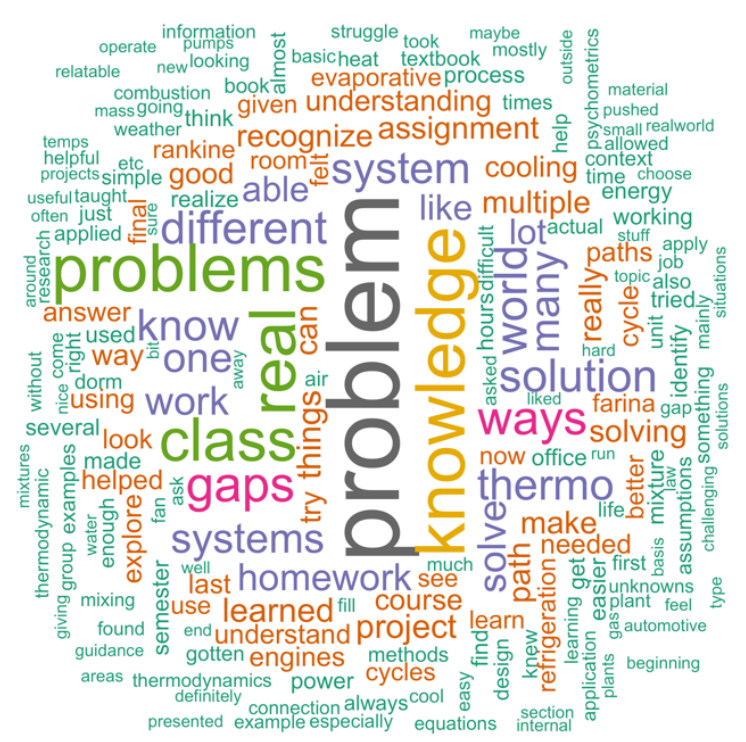

Figure 4. Student natural language summary of the open-ended essay questions.

Each of the students' essay questions were analyzed for trends, by learning objective, by an educational expert working with the instructor. For the first objective, "Ability to recognize and explore knowledge gaps," students reported the KEEN module helped them to recognize their own knowledge gaps and utilize mechanisms to remedy such gaps (63\%;n=32 students). Characteristic student statements:

- "I had to learn more about evaporative cooling to solve the problem."

- "[Instructor] did a good job telling us enough but not everything so HW problems were fair but challenging."

- “On homework, when I realize I didn't know what it means or how to do it, I go to office hours (this is the first semester I have) to ask questions."

- "I was able to identify that I needed to work on the 2nd law of thermodynamics 1 and in regards to entropy production."

For the second objective, "Ability to explore multiple solution paths," a majority of the students described how the KEEN module helped them realize how many different engineering issues can be solved in a variety of ways (67\%, 34 students).

- "Thermo problems can be solved multiple ways, I've come to realize."

- "I had to try to solve the problem different ways for the evaporative cooling project, and it was pretty easy to tell when I was wrong." 
- "There were many ways to reach a "solution" and the way we took it was the most logical to us."

- "Several topics in this class (especially mixtures) had several different solution paths we were able to use."

For the final learning objective, "Identify links between course knowledge and real-world systems," most of the students described how the KEEN module helped them make connections between engineering concepts and real world concepts (80\%, 41 students).

- "The evaporative cooling problem helped me see how thermo could be used in a real-life situation."

- "[Instructor] brought in an actual refrigeration unit one day and had us learn by actually analyzing the physical system."

- "A lot of times in this class a 2-D block diagram of a cycle became an actual real-world system. This connection was difficult to make before but this class really pushed for it."

- "I have been able to identify how simple things like the human body are thermodynamic systems."

- "This class did a better job than most of connecting "real world" to classroom. For example, automotive, refrigeration and dorm room problems."

\section{Conclusions}

A new classroom module was developed for engineering students to help them develop skills in psychrometrics, and to link real-world problems to thermodynamics. The module developed was tested in Spring, 2019.

In general, the module was rated highly by the students for all three learning objectives. The objective for identifying links between course knowledge and real world systems was statistically significantly higher $(p<.05)$, however, when compared to the other learning objectives.

The results indicate that an open-ended module of this type may be helpful for linking knowledge in a thermodynamics course. Psychrometrics is a difficult concept for many students, and an opportunity to make the knowledge more concrete is valuable. Future work will include adjusting this module to include an in-class worksheet focused on refrigeration methods.

\section{Acknowledgements}

The funding for this work was provided by the Kern Engineering Education Network (KEEN) as part of a grant to the University of Portland. Special thanks to Danielle Trollinger for assisting with the design of this module. 


\section{References}

1. KEEN. KEEN - The Framework [Internet]. [cited 2020 Jan 16]. Available from: https://engineeringunleashed.com/mindset-matters/framework.aspx

2. Maixner M, Baughn J. Teaching psychrometry to undergraduates. In: ASEE Annual Conference and Exposition, Conference Proceedings. 2007.

3. Shepard T, George C. Desalination Design Project for Thermodynamics Lab. In: ASEE Annual Conference and Exposition, Conference Proceedings. 2010. p. 15.345.

4. Peuker JM, Peuker S. Incorporating Active Learning into a Thermal System Design Lecture. In: ASEE Annual Conference and Exposition, Conference Proceedings [Internet]. Atlanta, GA; 2013 [cited 2020 Jan 17]. p. 23.727.1. Available from: https://peer.asee.org/incorporating-active-learning-into-a-thermal-system-design-lecture

5. Somerton C, Genik L. Teaching psychrometrics: A timely approach using active learning. In: ASEE Annual Conference and Exposition, Conference Proceedings. 2006.

6. Kresta S, Ayranci I. Psychrometric charts in color: An example of active learning for chemical engineering students and faculty members. Educ Chem Eng. 2018 Jan 1;22:149.

7. Coronella C. Project Based Learning In A First Year Chemical Engineering Course: Evaporative Cooling. In: ASEE Annual Conference and Exposition, Conference Proceedings [Internet]. 2006 [cited 2020 Jan 17]. p. 11.104.1. Available from: https://peer.asee.org/project-based-learning-in-a-first-year-chemical-engineering-courseevaporative-cooling

8. Berman ET, Wiyono A, Zakaria A, Supriatno S. Enhancing of Student Competency in Psychrometric Subjects Using the Edutainment Method. In Atlantis Press; 2019. 